\title{
Diversidade Sexual e Avaliação Psicológica: os Direitos Humanos em Questão
}

Sexual Diversity And Psychological Evaluation: Human Rights In Question

Diversidad Sexual Y Evaluación Psicológica: Los Derechos Humanos En Cuestión

Angelo Brandelli Costa \& Henrique Caetano Nardi

Universidade Federal do Rio Grande do Sul
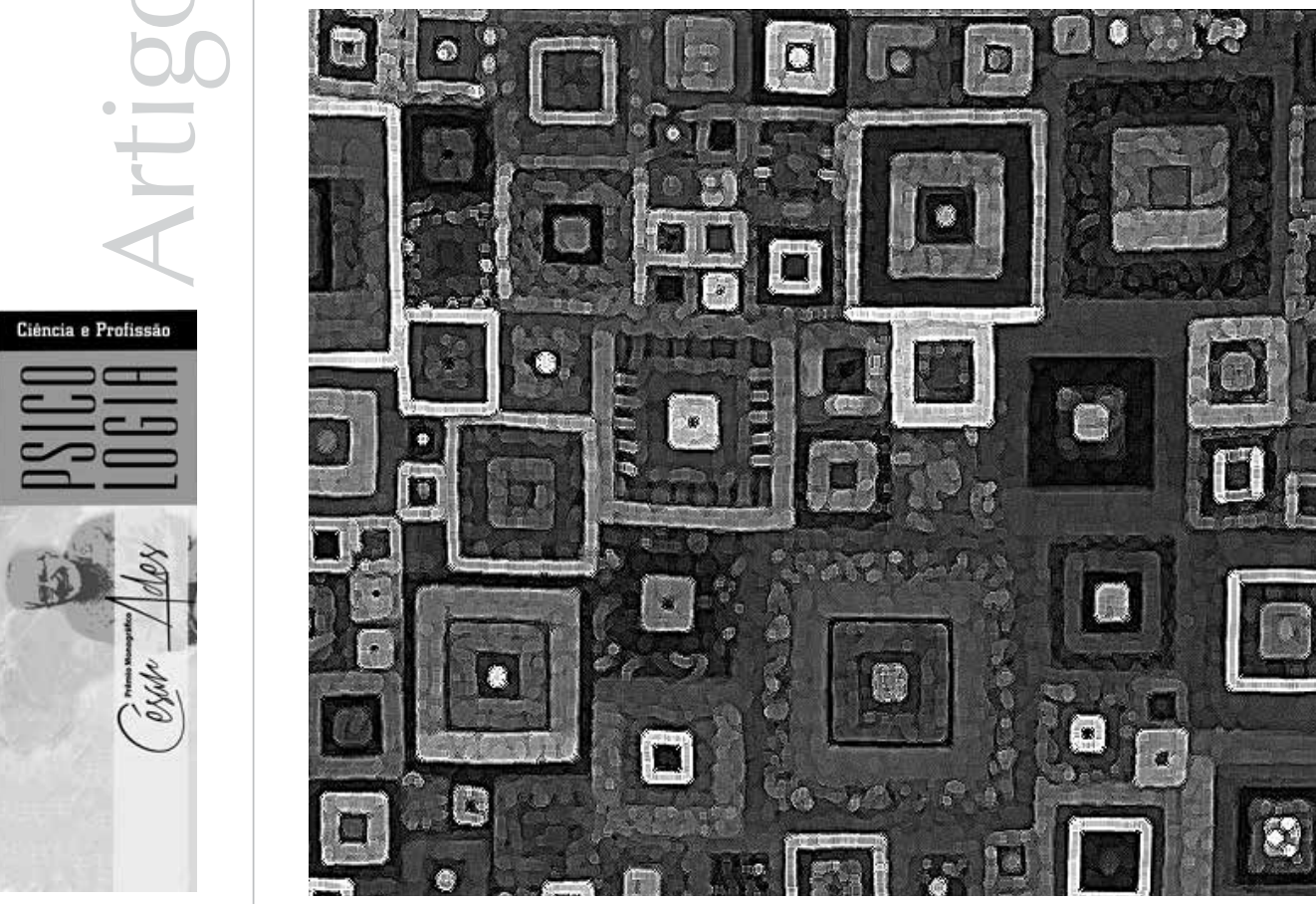
Resumo: Este estudo visa contribuir com o debate contemporâneo da relação entre Psicologia, direitos humanos e diversidade sexual. Na primeira parte, será exposto o debate acerca da relação entre direitos humanos e avaliação psicológica, suas potencialidades e limitações. Em seguida, serão discutidas as definições de direitos humanos e sua relação com a diversidade sexual. Na terceira parte, será apresentado o tratamento histórico que a Psicologia, especialmente a avaliação psicológica, deu às questões da diversidade sexual e suas repercussões à luz dos direitos humanos. A quarta parte analisará o Inventário Fatorial de Personalidade (IFP) identificando vieses discriminatórios. Por fim, será proposto o que se espera de uma avaliação psicológica atenta aos pressupostos éticos que embasam os direitos humanos e que contribua para a construção do conhecimento no século XXI.

Palavras-chave: Avaliação psicológica. Diversidade sexual. Direitos humanos. Igualdade social.
O autor agradece aos mestres Henrique Caetano Nardi e Denise Ruschel Bandeira pela orientação ao longo da escrita deste ensaio e aos amigos Heitor Thomé da Rosa Filho, Roger Raupp Rios e Pedro Paulo Bicalho pelos insights valiosos.

Abstract: This study aims to contribute to the contemporary debate in relation to psychology, human rights and sexual diversity. The first part will expose the current discussions about the relationship between human rights and psychological evaluation, their contributions and limitations. Then it will be discussed the definition of human rights and its relation to sexual diversity. The third part will present the historical treatment that psychology, especially the psychological evaluation gave to the issue of sexual diversity and its repercussion in the human rights. The fourth part will examine the Inventário Fatorial de Personalidade (IFP) identifying the discriminatory biases. Finally, it will be presented what it is expected of a psychology attentive to the ethical presuppositions that underlie human rights and that contribute to the building of 21st century knowledge. Keywords: Psychological assessment. Sexual diversity. Human rights. Social equality.

Resumen: Este estudio está orientado a contribuir con el debate contemporáneo de la relación entre la Psicología, los derechos humanos y la diversidad sexual. En la primera parte, será expuesto el debate acerca de la relación entre derechos humanos y evaluación psicológica, sus potencialidades y limitaciones. Enseguida, serán discutidas las definiciones de derechos humanos y su relación con la diversidad sexual. En la tercera parte, será presentado el tratamiento histórico que la Psicología, especialmente la evaluación psicológica, le dio a las cuestiones de la diversidad sexual y sus repercusiones a la luz de los derechos humanos. La cuarta parte analizará el Inventario Factorial de Personalidad (IFP) identificando aspectos discriminatorios. Por fin, será propuesto qué se espera de una evaluación psicológica atenta a los supuestos éticos que sustentan los derechos humanos y que contribuya para la construcción del conocimiento en el siglo XXI.

Palabras clave: Evaluación psicológica. Diversidad sexual. Derechos humanos. Igualdad social.

A Psicologia, e, especificamente, a avaliação psicológica, é capaz de dar conta dos desafios colocados pelos princípios éticos que guiam a perspectiva dos direitos humanos? Refletir sobre as práticas psicológicas a partir dos direitos humanos requer um posicionamento crítico, isto é, requer "pensar a formação e a atuação dos psicólogos inseridos em tal contexto de análise e convocá-los para pensar nos lugares que eles ocupam, nas subjetividades que eles estão produzindo" (Bicalho, Cassal, Magalhães, \& Geraldini, 2009 , p. 20). Soma-se a isso o reconhecimento de que o atual Código de Ética profissional não contempla diretamente todas as situações éticas relativas à avaliação psicológica: "Os avanços da ciência psicológica e as crescentes demandas sociais têm produzido novas situações para as quais muitas vezes não temos parâmetros sobre formas apropriadas de atuação" (Hutz, 2009, p. 297). Portanto, fomentar a discussão da interface entre avaliação psicológica e direitos humanos é fundamental para o estabelecimento de bases mais objetivas sobre as quais a atuação do psicólogo deve orientar-se. De outra maneira, corre-se o risco de confusão, de demagogia e de interpretações errôneas.

Um campo emblemático que permite ilustrar como a avaliação psicológica deve atentar para a promoção e a garantia dos direitos é o da diversidade sexual. A reflexão acerca da diversidade sexual torna-se ainda mais urgente diante de sua crescente visibilidade, graças, infelizmente, aos constantes relatos de agressão, violação de direitos, preconceito e discriminação (Costa, Peroni, Bandeira, \& Nardi, 2012), reflexões essas reconhecidas no âmbito da Psicologia por parte do Conselho Federal no caderno Psicologia e Diversidade Sexual: Desafios para uma Sociedade de Direitos (CFP, 2011). 
As várias reedições do

Código de

Ética atestam

essa tendência,

sendo que,

em sua última

revisão, logo no

primeiro princípio

fundamental,

lê-se que "o

psicólogo

baseará seu

trabalho no

respeito e na

promoção da

liberdade, da

dignidade, da

igualdade e da

integração do ser

humano, apoiado

nos valores que

embasam a

Declaração

Universal dos

Direitos Humanos"

(CFP, 2005, p. 7).
Objetivando colaborar para o aprofundamento desse debate, este texto percorrerá algumas etapas. Na primeira parte, será exposto o debate acerca da relação entre direitos humanos e avaliação psicológica, suas potencialidades e limitações. Em seguida, serão discutidas as definições de direitos humanos e sua relação com a diversidade sexual. Na terceira parte, será apresentado o tratamento histórico que a Psicologia, especialmente a avaliação psicológica, deu às questões da diversidade sexual e suas repercussões à luz dos direitos humanos. A quarta parte analisará o Inventário Fatorial de Personalidade (IFP) identificando vieses discriminatórios. Por fim, será proposto o que se espera de uma avaliação psicológica atenta aos pressupostos éticos que embasam os direitos humanos e que contribua para a construção do conhecimento no século XXI.

\section{Direitos humanos e avaliação psicológica}

Desde a década de 70, com a publicação do primeiro Código de Ética profissional, o Conselho Federal de Psicologia (CFP) tem atentado para a temática dos direitos humanos. Essa discussão se fortaleceu durante a década de 90 com a criação da Comissão Nacional de Direitos Humanos do CFP e, posteriormente, com a obrigatoriedade de se criar comissões de direitos humanos nos Conselhos Regionais. As várias reedições do Código de Ética atestam essa tendência, sendo que, em sua última revisão, logo no primeiro princípio fundamental, lê-se que "o psicólogo baseará seu trabalho no respeito e na promoção da liberdade, da dignidade, da igualdade e da integração do ser humano, apoiado nos valores que embasam a Declaração Universal dos Direitos Humanos" (CFP, 2005, p. 7).

Embora a preocupação mais genérica com os direitos humanos figurasse em algum grau nas regulamentações do CFP, a sua relação com a avaliação psicológica é recente. Apenas em 2010 surgem textos que discutem claramente tal relação, especialmente com as publicações: Avaliação Psicológica: Diretrizes na Regulamentação da Profissão (2010), Ano da Avaliação Psicológica - Textos Geradores (2011) e o Relatório do Ano Temático da Avaliação Psicológica (2013). Dois argumentos recorrentes nesses textos são, em primeiro lugar, o reconhecimento de que os testes psicológicos foram criados em uma perspectiva adaptacionista e que "o ato de avaliar implica a emissão de juízos e valores" (Anache, 2011, p. 17); em segundo lugar, a ideia de que, para estar de acordo com os direitos humanos, é necessário "atentar para as características técnicas dos instrumentos (como as diferentes evidências de validade e fidedignidade)" (Reppold, 2011, p. 24).

O primeiro ponto destaca que, historicamente, a avaliação psicológica fomentou práticas de exclusão social, sobretudo dado que a avaliação "era reduzida à administração de testes isolados sem levar em consideração o contexto da aplicação, nem mesmo a necessidade de adaptação dos instrumentos às normas locais" (Reppold, 2011, p. 23). Esse tipo de prática ainda se faz presente, uma vez que a maioria das infrações éticas denunciadas ao Conselho Federal de Psicologia trata de queixas com respeito à avaliação psicológica, como: a extrapolação do uso dos testes a situações diferentes daquelas para as quais foram projetados, declarações falsas ou limitadas a partir dos testes e falta de confidencialidade (Anache \& Reppold, 2010).

O segundo ponto remete à responsabilidade científica, ou seja, à constatação de que, a partir da qualidade dos testes, verificada em estudos que demonstram seus fundamentos científicos, evidências de validade e fidedignidade e respeito à complexidade das técnicas, estaria garantida a atenção aos direitos humanos. O caminho para levar em conta essa responsabilidade tem sido 
1 Em março de 2012, o CFP publica

a Resolução CFP no 005/2012, que modifica a Resolução

CFP n.․ 002/2003.

A nova resolução

inclui os requisitos éticos e de defesa dos direitos humanos que os testes psicológicos

deverão atender

para que possam ser reconhecidos como testes em condição de uso. A resolução estabelece, dentre outras regras, que os psicólogos não poderão elaborar, validar, traduzir, normatizar, comercializar e

fomentar instrumentos ou técnicas psicológicas para criar, manter ou reforçar preconceitos, estigmas ou

estereótipos. Além disso, estabelece que é vedado ao psicólogo, na produção,

validação, tradução, normatização,

comercialização e aplicação de testes psicológicos: a)

realizar atividades

que caracterizem negligência, preconceito,

exploração, violência, crueldade ou opressão,

b) induzir a convicções políticas, filosóficas, morais, ideológicas, religiosas, raciais, de orientação sexual, c) favorecer o uso de conhecimento da ciência psicológica e normatizar a utilização de práticas psicológicas como instrumentos

de castigo, tortura ou qualquer forma de violência (CFP, 2012a). reportar-se ao Sistema de Avaliação dos Testes Psicológicos (SATEPSI) criado pela Resolução CFP no 002/2003. A resolução estabelece que deve ser criado de um sistema de avaliação por pares das diferentes técnicas psicológicas disponíveis no Brasil de acordo com critérios técnicos mínimos, a saber:

I - apresentação da fundamentação teórica do instrumento, com especial ênfase na definição do construto, sendo o instrumento descrito em seu aspecto constitutivo e operacional, incluindo a definição dos seus possíveis propósitos e os contextos principais para os quais ele foi desenvolvido; II - apresentação de evidências empíricas de validade e precisão das interpretações propostas para os escores do teste [...]; III - apresentação de dados empíricos sobre as propriedades psicométricas dos itens do instrumento; IV - apresentação do sistema de correção e interpretação dos escores [...]; V - apresentação clara dos procedimentos de aplicação e correção, bem como as condições nas quais o teste deve ser aplicado [...]; VI - compilação das informações indicadas acima, bem como outras que forem importantes em um manual [...] (CFP, 2003, pp. 2-3)

A prática profissional dos psicólogos que empregam essas técnicas passa então a ser vinculada à utilização daqueles instrumentos listados pelo sistema. A esse respeito:

O SATEPSI eleva a qualidade dos instrumentos de avaliação psicológica utilizados pelos profissionais da área e prima pela atenção aos direitos humanos, uma vez que baseia os critérios de avaliação da qualidade dos testes em estudos que comprovem seus fundamentos científicos (isto é, que sejam baseados em evidências empíricas e normas atualizadas). (Reppold, 2011, p. 25)

Ou ainda:

Os critérios [do SATEPSI] são meios de certificar a qualidade dos instrumentos e estão em direta consonância com o sentido mais amplo dos princípios fundamentais que são tratados na Declaração dos Direitos Humanos, pois buscam reconhecer instrumentais que atingem padrões de qualidade mínimos para uma prática cientificamente reconhecida, como forma de colocar o conhecimento e os instrumentos psicológicos disponíveis à sociedade, de maneira responsável. (Primi, 2011, p. 56)

É evidente que a implementação do SATEPSI modificou o panorama de mau uso das técnicas de avaliação psicológica no Brasil. Antes do estabelecimento do sistema, como relembra Hutz (2009), os testes utilizados no Brasil corriqueiramente utilizavam dados oriundos de países economicamente desenvolvidos. As normas relativas a esses países, entre outras, induziam a uma avaliação não condizente com indivíduos de outros grupos sociais que não os do contexto de origem dos instrumentos. O controle exercido pelo CFP através do SATEPSI elevou a qualidade dos testes disponíveis no País e a atuação dos psicólogos nessa área. Por outro lado, ainda que a resolução que regulamenta o SATEPSI afirme ser necessária a "revisão periódica das condições dos métodos e técnicas utilizados na avaliação psicológica, com o objetivo de garantir serviços com qualidade técnica e ética à população usuária desses serviços" (CFP, 2003, p. 1), não há menção, tanto na Resolução CFP no 002/2003 quanto na Resolução CFP no 006/2004 que a altera, aos procedimentos a serem adotados para que se assegure essa qualidade ética. Além disso, não há uma só menção nessas resoluções a respeito de direitos humanos e de seus princípios, ficando as resoluções restritas a critérios técnicos ${ }^{1}$ Esses pontos de vista parecem sustentar, por um lado, a crença de que, ao se estabelecerem critérios psicométricos mínimos de validade e de fidedignidade dos instrumentos, também se garantirão critérios éticos, ou seja, a crença na ambivalência entre critérios técnicos e 
éticos. Por outro lado, adotam uma visão muito ampla de direitos humanos, que leva a uma noção genérica de violação desses direitos; perde-se, assim, a especificidade dos direitos violados em questão. Para evitar os riscos de ineficácia da aplicação dos princípios dos direitos humanos presentes nesses pontos de vista, faz-se necessário tanto estabelecer de que forma se pode garantir a qualidade ética dos instrumentos (se somente através da responsabilidade científica ou não) quanto distinguir, dentre os direitos humanos, aqueles fundamentais, para que se identifique qual perspectiva ética se busca.

\section{Direitos humanos e diversidade sexual}

Direitos humanos são usualmente definidos como direitos fundamentais inalienáveis e inerentes a todas as pessoas, simplesmente porque ele ou ela é um ser humano (Sepúlveda, van Banning, Gudmundsdóttir, Chamoun, \& van Genugten, 2004), e também podem ser entendidos como o conjunto de valores consagrados em instrumentos jurídicos destinados a fazer respeitar e concretizar as condições de vida que possibilitem a todo ser humano manter e desenvolver suas qualidades peculiares. Os direitos humanos diferem de outros tipos de direito por duas razões centrais: 1) são universais (aplicáveis em todos os lugares) e 2) são igualitários (os mesmos para todos). Desde a fundação da Organização das Nações Unidas, em 1945, a noção de direitos humanos ganhou importância. No entanto, foi a Declaração Universal dos Direitos Humanos, lançada em 10 de dezembro de 1948, que fundou os alicerces do conceito moderno. A declaração é constituída por 30 artigos. Dentre eles, é possível distinguir aqueles que dizem respeito a necessidades materiais e não materiais que, caso não sejam providas, ferirão a dignidade da existência humana. Esses direitos fundamentais são aqueles a que deve ser dada absoluta prioridade nas políticas nacionais e internacionais: o direito à vida, o direito a um nível mínimo de segurança, a inviolabilidade da pessoa humana, a liberdade física e a não discriminação. Eles ainda incluem a liberdade de pensamento, o direito a nutrição adequada, a vestimenta, a abrigo e a assistência à saúde (Sepúlveda et al., 2004).

Por sua vez, a temática dos direitos sexuais ganha fôlego com a construção, no âmbito dos movimentos de mulheres, da terminologia saúde e direitos reprodutivos e das estratégias derivadas da política de enfrentamento ao HIV/ AIDS. Analistas apontam como fundamental para a afirmação dos princípios associados aos direitos sexuais a Conferência Internacional de População e Desenvolvimento realizada no Cairo, em 1994, e a IV Conferência sobre a Mulher, realizada em Pequim, em 1995 (Simões \& Facchini, 2009). A partir dessas conferências, o campo político relacionado à saúde e aos direitos reprodutivos passa a congregar uma série de reivindicações regulatórias nos âmbitos da violência sexual, DST/AIDS, nupcialidade, divórcio, separação e adultério, prostituição e orientação sexual, sob a égide, então, de direitos sexuais.

Nos debates sobre diversidade sexual e direitos humanos, cuja invocação se revelou mais fundamental e capaz de proteger os homossexuais, foram discutidos o direito de privacidade e liberdade, o direito de igualdade e o de proteção da dignidade da pessoa humana (Rios, 2011). O direito de privacidade protege os homossexuais face à discriminação em virtude da sua orientação sexual com respeito à vida privada. A privacidade possibilita aos indivíduos, de forma autônoma, a tomada de decisões quanto aos objetivos e aos estilos de vida; já o direito à igualdade veda tratamentos prejudiciais baseados na orientação sexual. Desse modo, restrições de direitos não autorizadas em lei (por ex., a proibição de manifestações 
de afeto entre homossexuais idênticas àquelas admitidas para heterossexuais) bem como restrições de direitos fundadas em preconceito (por ex. restringir a adoção a casais heterossexuais sob o pretexto de danos à criança) caracterizam violação do direito à igualdade. Por fim, a proteção da dignidade humana é compreendida como o reconhecimento do valor único de cada vida humana, merecedora de respeito e consideração. Na esfera da sexualidade, esse direito pressupõe que ninguém seja afrontado em virtude de orientação sexual (Rios, 2011).

\section{Psicologia e diversidade sexual}

E o que a Psicologia tem a dizer sobre isso? Historicamente, a Psicologia teve papel central na legitimação e na perpetuação do estigma relacionado às orientações não heteronormativas (Gilman, 1985). Embora relatos do desejo e de comportamentos não heterossexuais remontem a diferentes sociedades e períodos históricos, a ideia de que esses comportamentos são dignos de atenção científica (Foucault, 1998) começou a ganhar importância no final do século XIX, graças à ciência médica e jurídica da época. Isso se deu através da implantação de um discurso científico que visava a normalizar a sexualidade através da sua submissão a uma taxonomia rígida e valorativa, ou seja, a ciência sobre a sexualidade teve como contrapartida o desenvolvimento de uma clínica das perversões sexuais, na qual a heterossexualidade monogâmica foi considerada padrão de normalidade, e as demais práticas sexuais e afetivas, especialmente a homossexualidade, foram consideradas patologia (Herek, 2010).

Boa parte do século XX testemunhou a cristalização da interpretação dominante da ciência psicológica a respeito da homossexualidade. Nas duas primeiras edições do Manual Diagnóstico de Doenças
Psiquiátricas da American Psychiatric Association, o homossexualismo figurava entre os transtornos de identidade sexual. Respaldados por essas classificações diagnósticas, muitos Estados norte-americanos aprovaram leis que feriam a compreensão contemporânea de direitos sexuais. Essas leis, sob a figura da sodomia, garantiam a permanência indefinida dos homossexuais em instituições terapêuticas até que fossem declarados curados (Herek, 2010). Técnicas que hoje podemos considerar tortura foram utilizadas para alterar o comportamento sexual (Gilman, 1985). Esses tratamentos foram responsáveis por intenso sofrimento psíquico e físico, levando, em muitos casos, a sequelas permanentes e ao suicídio (Haas et al., 2010). Durante esse período, abundam instrumentos desenvolvidos para o diagnóstico da homossexualidade, dentre eles, os indicadores diagnósticos da homossexualidade no desenho da figura humana (Gardner, 1969) e a interpretação do Teste Rorschach, segundo Schaffer (como citado por Andersen \& Seitz, 1969). Esses testes buscavam diferenças clínicas entre heterossexuais e homossexuais, diferenças que, quando constatadas, justificavam déficits psicológicos dos homossexuais em relação aos heterossexuais, contribuindo para a manutenção do estatuto de patologia. Esses trabalhos não levavam em conta, por exemplo, que tais problemas poderiam ser fruto da grande segregação social e do estigma vivenciado por esse grupo.

O panorama começa a mudar no final da década de 40, com a publicação de uma série de estudos oriundos da Antropologia, que mostravam que a homossexualidade está presente em diferentes culturas. É também dessa época o trabalho de Alfred Kinsey, Pomeroy e Martin colaboradores, que, em 1948, publicam seu livro sobre o comportamento sexual dos homens americanos constatando que experiências homossexuais são relativamente comuns. São 
da mesma época os trabalhos seminais de Evlyn Hooker $(1957,1958)$. Essa pesquisadora conduziu o primeiro estudo comparando amostras não clínicas de homossexuais e heterossexuais buscando evidência do caráter patológico da homossexualidade. Hooker aplicou o Teste Rorschach em 30 homens heterossexuais e em 30 homossexuais, nenhum dos quais com indicadores de psicopatologia. Em seguida, Hooker pediu para que avaliadores cegos identificassem de qual grupo provinham os protocolos e quais deles apresentavam alguma caraterística psicopatológica. Os juízes classificaram a maioria dos homossexuais e heterossexuais da mesma forma e na categoria mais alta de ajustamento social. Hooker concluiu que a homossexualidade não constituía uma entidade clínica e não deveria estar associada à psicopatologia. Além disso, o trabalho desse autor questionou o uso da avaliação psicológica para identificar a orientação sexual, afirmando que "sua validade duvidosa torna o seu valor questionável" (1958, p. 51). Infelizmente, essas pesquisas foram por muito tempo ignoradas, e as orientações não heteronormativas foram acriticamente patologizadas e erroneamente tratadas pela Psicologia até meados da década de 70. Outras pesquisas que supostamente apoiavam a noção da homossexualidade como psicopatologia foram revisadas (Gonsiorek, 1991), percebendo-se uma variedade de problemas, incluindo falta de clareza conceitual, classificação inadequada dos participantes, grupos de comparação inapropriados, amostragem falha, não observância de fatores sociais possivelmente correlacionados e uso de medidas questionáveis.

Em 1973, a American Psychiatric Association remove a homossexualidade da terceira edição do seu Manual Diagnóstico de Doenças Mentais (DSM III) graças a pressões do movimento pelos direitos sexuais LGBT e à falta de bases empíricas que associassem a homossexualidade a indicadores de transtornos psicológicos. No momento em que a homossexualidade deixa de ser tomada como um problema médico, a atenção nesse campo recai sobre aqueles que a consideram um desvio moral, uma doença ou perturbação. George Weinberg publica, em 1972, Society and the Healthy Homossexual (A Sociedade e o Homossexual Saudável), introduzindo o termo homofobia: “Homofobia é o pavor de estar próximo a homossexuais - e no caso dos próprios homossexuais, auto-aversão" (Weinberg, 1972, p.8). O livro popularizou o termo e introduziu o preconceito contra orientações não heterossexuais como um problema acadêmico digno de análise e intervenção. $\mathrm{O}$ termo foi adotado por ativistas e incorporado pela Academia, especialmente dentro do campo de estudos do preconceito, o qual tinha se preocupado em décadas anteriores com os temas de anti-semitismo, racismo e sexismo (Young-Bruehl, 1996).

Desde essa época, a Psicologia tem se dedicado a reverter os danos causados pelo estigma que até então tinha ajudado a construir. Em 1975, a American Psychological Association publica um documento em que afirma que a homossexualidade por si só não implica prejuízo, e ainda apela para que "todos os profissionais de saúde tomem a iniciativa de remover o estigma de doença mental que foi longamente associado às orientações homossexuais" (Conger, 1975, p. 633). Quase 25 anos mais tarde, o mesmo acontece no Brasil com a Resolução CFP no 001/99, que, no seu segundo artigo, informa que os psicólogos deverão contribuir "para uma reflexão sobre o preconceito e o desaparecimento de discriminações e estigmatizações contra aqueles que apresentam comportamentos ou práticas homoeróticas" (p. 2). As pesquisas, que, até o momento, eram voltadas para a cura e os diagnósticos da homossexualidade, passam a buscar as raízes do preconceito e 
as estratégias para revisar práticas psicológicas discriminatórias, dentre elas a avaliação psicológica (Snyder, 2011). Em 1991, a APA publica um documento orientando a revisão das práticas psicológicas levando em conta vieses preconceituosos (APA, 1991), e, devido à visibilidade abjeta e patologizada a que a população LGBT foi sujeita, a validade de diversos instrumentos passou a ser questionada tendo em vista essas populações.

\section{Vieses discriminatórios na avaliação psicológica}

Chernin, Holden e Chandler (1997) revisaram uma série de testes de grande uso nos Estados Unidos, dentre os quais o Inventário Beck de Depressão e o Inventário Multifásico de Personalidade de Minnesota - MMPI. Os autores sugerem três vieses que devem ser levados em conta quando se avaliam instrumentos tendo em vista as populações LGBT: de omissão, de conotação e de contiguidade. Oviés de omissão ocorre quando a linguagem utilizada pelo instrumento ignora a possibilidade de o respondente pertencer a um grupo minoritário. O segundo tipo de viés é o de conotação, e ocorre quando palavras de conotação negativa são associadas a grupos minoritários. Palavras como homossexual, por exemplo, aparecem em conjunto com termos como alcoolista, fetichista e desajustado, sugerindo uma categorização negativa da

2 Em outubro de 2012, o CFP divulgou uma nota de orientação aos psicólogos(as) a respeito do IFP, recomendado cautela no seu uso, uma vez que "supostamente possa infringir preceitos constitucionais fundamentais" e reforçando seu parecer favorável para uso (CFP, 2012b). homossexualidade. O terceiro viés é o de contiguidade, que se dá quando escalas com o objetivo de avaliar psicopatologia aparecem em conjunto com escalas cujo objetivo é caracterizar grupos minoritários.

Usando uma metodologia similar, Pope (1992) apontou vieses preconceituosos em outros instrumentos, dentre eles o Edwards Personal Preference Schedule (1954). O teste apresenta uma versão nacional, amplamente utilizada em nosso contexto, chamada de Inventário Fatorial de Personalidade (Pasquali, Azevedo, \& Ghesti, 1997), que visa a avaliar o indivíduo em 15 necessidades psicológicas, a saber: assistência, dominância, ordem, denegação, intracepção, desempenho, exibição, afago, mudança, persistência, agressão, deferência, autonomia, afiliação e heterossexualidade. Cada necessidade compõe uma escala de nove itens que devem ser avaliados em uma escala tipo Likert de 7 pontos, que vai de "1 = Nada característico" até " $7=$ Totalmente característico". Além disso, o teste possui uma escala de desejabilidade social (12 itens) e outra de mentira ou validade (8 itens), totalizando 155 itens. A adaptação brasileira foi realizada por Pasquali, Azevedo e Ghesti (1997) com uma amostra de 3.399 sujeitos oriundos de 11 Estados brasileiros. O instrumento foi avaliado e aprovado para uso pelo SATEPSI em 2003, sendo que, na última publicação da lista de testes com parecer favorável para uso, em novembro de 2012, o inventário mantinha-se presente ${ }^{2}$.

A análise do IFP permite constatar alguns vieses, de acordo com Chernin, Holden e Chandler (1997). No que diz respeito aos itens que compõem o instrumento, é possível encontrar exemplos do viés de omissão. $\mathrm{Na}$ escala de heterossexualidade (HT), itens como "gosto de beijar pessoas atraentes do sexo oposto" aparecem ao lado de "gosto de ficar sexualmente excitado", (Pasquali, Azevedo, \& Ghesti, 1997, p. 26). Isso sugere que o teste busca avaliar interesse sexual heterossexual, ficando o interesse sexual homossexual omitido do instrumento, uma vez que não é possível, ao mesmo tempo, sentir-se atraído por pessoas do mesmo sexo e interessado em excitação sexual. A escala HT foi originalmente criada para avaliar "O desejo de manter relações, desde românticas até sexuais, com indivíduos do sexo oposto. O sujeito com alto índice nesse fator é fascinado por sexo e por assuntos afins" (p. 39), no entanto, no manual do instrumento, um jovem com escores extremamente baixos nessa escala é interpretado da seguinte forma: "para um jovem de tal idade (22 anos), o 
interesse pelo sexo parece anormalmente ausente (seria repressão?)" (p. 57). O teste não supõe que o jovem em questão possa ser homossexual; no lugar disso, interpreta o escore como heterossexualidade reprimida, ou seja, de forma negativa, o que constitui um claro viés de conotação. Por fim, a mera presença da escala HT no teste constitui viés de contiguidade, já que o IFP é amplamente utilizado em contextos subclínicos (Peres \& Santos, 2006; Irigaray \& Schneider 2007), em que a homossexualidade é associada, implicitamente, à psicopatologia. É digno de nota que mesmo os critérios técnicos apontam problemas na escala HT. Quando o teste é analisado quanto à sua estrutura fatorial, as necessidades associam-se entre si, exceto a heterossexualidade (Pasquali, Azevedo, \& Ghesti, 1997), o que coloca em questão a relevância dessa escala em relação às demais dimensões do construto avaliado. O mesmo acontece em uma revisão recente da estrutura fatorial do IFP, que apontou que "a unidimensionalidade dos fatores pode ser questionada, o que sugere, pelo menos, que os sujeitos perceberam conteúdos distintos em relação aos itens que formam cada fator" (Araújo, 2004, p. 9).

O IFP já passou pelo escrutínio de pesquisadores brasileiros em pelo menos duas oportunidades. A qualidade dos testes de personalidade disponíveis no mercado brasileiro foi avaliada (Noronha, 2002) de acordo com os seguintes critérios: qualidade do material, da documentação, dos itens e das instruções. Por qualidade de material, entendeu-se a qualidade dos objetos, dos materiais impressos (folha de resposta, cadernos e outros), do manual e dos livros suplementares. A qualidade da documentação referia-se à descrição clara e completa das características técnicas, fundamentadas em dados e referências satisfatórias. A qualidade dos itens, por sua vez, dizia respeito à redação e à adequada seleção dos itens, e, por fim, as instruções foram avaliadas com qualidade quando se apresentavam de maneira clara, precisa e adequada à população para a qual o teste se destinava. Concluiu-se que, dentre os instrumentos que apresentavam pontuação máxima em todos os critérios, estava o IFP. Em outro estudo (Lima \& Noronha, 2005), psicólogos e estudantes de pós-graduação em Psicologia foram solicitados a avaliar a qualidade de testes, dentre eles o IFP. No primeiro bloco da avaliação, estavam informações pertinentes relacionadas ao nome, editora, ano de publicação e variável avaliada, entre outras; já o segundo bloco relacionava informações sobre a construção e os parâmetros psicométricos. O grupo dos pós-graduandos entrou em consenso quanto à alta qualidade do teste; o grupo dos psicólogos, no entanto, apontou falhas, mas elas diziam respeito apenas à redação do seu manual.

Dessa forma, apesar de ter parecer favorável do SATEPSI e de ser um ótimo instrumento na opinião de pesquisadores, de estudantes e de psicólogos que atuam na área, fica evidente que os critérios de reconhecimento e de validação do instrumento analisado não estão totalmente de acordo com os princípios de promoção e de garantia dos direitos humanos. $\mathrm{O}$ instrumento fere claramente o direito à proteção da dignidade humana, uma vez que trata a homossexualidade de maneira negativa, e o direito de igualdade, já que parte do pressuposto de que o respondente do teste é heterossexual. Além disso, o uso indiscriminado desse instrumento pode promover encaminhamentos equivocados com base na interpretação dos seus resultados, como no caso da seleção de pessoal em que o IFP é amplamente utilizado. Isso fica explícito no relato de um processo julgado pelo Juiz federal Roger Raupp Rios (comunicação pessoal, $31 / 10 / 2011^{13}$ segundo o qual: 
Em um processo judicial se discutiu a eliminação em concurso público para cargo de agente policial federal. $\mathrm{O}$ autor foi considerado inapto no processo seletivo, em virtude de laudo psicológico. Requereu em juízo o acesso ao conteúdo do laudo e impugnou o motivo da exclusão, qual seja, não ter satisfeito determinada escala de heterossexualidade, apontada pelo avaliador como necessária para o exercício do cargo. Uma vez chamada para explicar em que consistia tal escala, a administração limitou-se a indicar como parâmetro a média alcançada pelos concorrentes na tal escala, sem justificar qual a relação de tal índice de heterossexualidade com o exercício do cargo, nem fornecer elementos objetivos acerca dela. Considerar a orientação sexual como impedimento para assumir cargo é violar o direito humano de igualdade.

\section{Considerações finais}

No exemplo citado, percebe-se como um instrumento pode estar em perfeita harmonia com os critérios técnicos estabelecidos e com o sistema regulatório, i.e., ser válido na opinião dos profissionais da área e, mesmo assim, estar em desacordo com critérios éticos. A discussão centrou-se na questão da diversidade sexual, mas o mesmo pode estar ocorrendo em outras temáticas que envolvem marcadores sociais, como aqueles ligados a classe, idade, escolaridade, raça/cor e religião, entre outros. Convém perguntar por que isso tem ocorrido:

A teoria ainda é, infelizmente, a parte mais fraca da pesquisa e do conhecimento psicológicos, o que tem como consequência a precariedade dos atuais instrumentos psicométricos e medidas nesta área. [...] Apesar do avanço e da sofisticação estatísticos na psicometria, parece ser essa fraqueza da base teórica que vem maculando a imagem dos procedimentos psicométricos de observação dos fenômenos psicológicos. (Pasquali, 2010, pp. 166-167)

O IFP é baseado na teoria das necessidades psicológicas básicas de Murray (1938), e é evidente que temos melhores noções de personalidade hoje do que tínhamos na época da criação da teoria que embasa o instrumento. Revisões das teorias que embasam os testes são necessárias, mas é preciso ir além. A prática psicológica tem constituído ferramenta de adequação e de ajustamento por não se perguntar o suficiente a respeito de suas técnicas, que são datadas historicamente, instituindo, dessa forma, "modelos de ser e de estar no mundo segundo padrões de normalidade produzidos como únicos e verdadeiros, inferiorizando e desqualificando os lugares ocupados pelos chamados diferentes, anormais, perigosos" (Bicalho, 2011, p. 90). Para que se contemplem princípios de qualidade ética na avaliação psicológica, de acordo com os direitos humanos, essas diferenças precisam estar contempladas, não excluídas.

No Brasil, a Psicologia avançou no reconhecimento e na promoção dos direitos humanos em sua relação com a avaliação psicológica ao ser publicada a Resolução no 005, de 2012, porém, muitos desafios precisam ser enfrentados. A psicologia norte-americana é um exemplo de como uma instituição que teve um papel central na legitimação de um estigma foi capaz de reconhecer sua cumplicidade nesse processo e de trabalhar para desfazer seus efeitos negativos. O presente artigo sinaliza o problema dos vieses discriminatórios presentes na avaliação psicológica, há muito estudados no contexto estadunidense. Em um país caracterizado por diferenças sociais, culturais e econômicas tão marcantes como o Brasil, o trabalho de revisão de técnicas psicológicas deve ser constante, e os profissionais formados na área precisam ser capazes de realizar tal revisão.

Uma direção para essa revisão pode ser extraída do artigo de Herek e colaboradores (1991). A partir das posições dos autores, é possível observar algumas questões. Esse instrumento 
ignora ou nega a existência de algum grupo social? Esse instrumento estigmatiza algum grupo social? Esse instrumento reflete estereótipos a respeitos desses grupos? Esse instrumento sugere implicitamente que as características avaliadas são causadas por algum atributo intrínseco desses grupos? Os itens contemplam a diversidade? Quanto à amostra: A amostra é representativa? Ela inclui diversidade o suficiente para permitir uma interpretação acurada? Já quanto ao processo de interpretação: $\mathrm{O}$ processo de aplicação do instrumento reforça estigmas, tem efeitos negativos nas populações que tem como alvo? As características avaliadas reforçam problemas ou patologias nesses grupos? A linguagem da interpretação apresenta vieses discriminatórios?

Para que se a Psicologia contribua para a construção do conhecimento no século XXI, deve-se ter em mente que a investigação dos seus pressupostos, no que diz respeito a vieses discriminatórios, é um importante passo para que a prática psicológica sirva para todos e todas, independentemente de suas diferenças. 
Angelo Brandelli Costa

Mestre em Psicologia Social pela Univesidade Federal do Rio Grande do Sul, Porto Alegre - RS - Brasil.

E-mail: brandelli.costa@ufrgs.br

\section{Henrique Caetano Nardi}

Doutor em Sociologia pela Universidade Federal do Rio Grande do Sul e docente do Instituto de Psicologia da Universidade Federal do Rio Grande do Sul, Porto Alegre - RS - Brasil.

E-mail: hcnardi@gmail.com

Endereço para envio de correspondência:

Universidade Federal do Rio Grande do Sul

Rua Ramiro Barcelo, 2600. CEP: 90040-060. Porto Alegre, RS. 
Anache, A. A. (2011). Notas introdutórias sobre os critérios de validação da avaliação psicológica na perspectiva dos direitos humanos. In Conselho Federal de Psicologia (Org.), Ano da Avaliação Psicológica - Textos Geradores (pp. 17-20). Brasília, DF: Autor.

Anache, A. A., \& Reppold, C. T. (2010). Avaliação psicológica: implicações éticas. In Conselho Federal de Psicologia. Avaliação psicológica: diretrizes na regulamentação da profissão (pp. 57-86). Brasília, DF: Autor.

Andersen, D. O., \& Seitz, F. C. (1969). Rorschach diagnosis of homosexuality: Schafer's content analysis. Journal of Projective Techniques \& Personality Assessment, 33(5), 406-408.

Araújo, R. M. (2004). Análise da estrutura fatorial do Inventário Fatorial de Personalidade - IFP. Universitas: Ciências da Saúde, 2(1), 1-10. doi: 10.5102/ucs.v2i1.519

Bicalho, P. P. G., Cassal, L. C. B., Magalhães, K. C., \& Geraldini, J. R. (2009). Formação em psicologia, direitos humanos e compromisso social: a produção micropolítica de novos sentidos. Boletim Interfaces da Psicologia da UFRuralRJ, 2, 20-35.

Bicalho, P. P. G. (2011). Ética e direitos humanos sob o crivo da avaliação psicológica: validade e fidedignidade em questão. In Conselho Federal de Psicologia. Ano da Avaliação Psicológica - Textos Geradores (pp. 89-94). Brasília, DF: Conselho Federal de Psicologia.

Chernin, J., Holden, J. M., \& Chandler, C. (1997). Bias in psychological assessment: Heterosexism. Measurement and Evaluation in Counseling and Development, 30, 68-76.
Conger, J. J. (1975). Proceedings of the American Psychologica Association, Incorporated, for the year 1974: Minutes of the annual meeting of the Council of Representatives. American Psychologist, 30, 620-651. doi: 10.1037/h0078455

Conselho Federal de Psicologia. (2003, dez.). Define e regulamenta o uso, a elaboração e a comercialização de testes psicológicos e revoga a Resolução CFP n 025/2001. Resolução CFP n 002, de 24 de março de 2003. Recuperado em 30 dezembro, 2012, de http://pol.org.br/legislacao/pdf/resolucao2003_2.pdf

Conselho Federal de Psicologia. (2004). Altera a Resolução CFP n. ${ }^{\circ}$ 002/2003. Resolução CFP $n^{\circ}$ 006, de 28 de junho de 2004 Recuperado em 30 dezembro, 2012, de http://www2.pol. org.br/satepsi/CD_testes/pdf/Resolu\%E7\%E3o\%20CFP\%20 n\%BA\%20006-04.p.pdf.

Conselho Federal de Psicologia. (2005, jul.). Resolução CFP $n^{\circ}$ 010, de 21 de julho de 2005. Aprova o Código de Ética Profissional do Psicólogo. Recuperado em 30 dezembro, 2012, de http://www.pol.org.br/pol/export/sites/default/pol/legislacao/ legislacaoDocumentos/resolucao2005_10.pdf

Conselho Federal de Psicologia. (2011). Psicologia e diversidade sexual: desafios para uma sociedade de direitos. Brasília, DF: Conselho Federal de Psicologia. Recuperado em 30 dezembro, 2012, de: http://www.pol.org.br/pol/export/sites/default/pol/ publicacoes/publicacoesDocumentos/Diversidade_Sexual_Final.pdf

Conselho Federal de Psicologia. (2012a). Altera a Resolução CFP n. ${ }^{\circ}$ 002/2003, que define e regulamenta o uso, a elaboração e a comercialização de testes psicológicos. Resolução CFP $n^{\circ}$ 005, de 8 de março de 2012. Recuperado em 30 dezembro, 
2012, de: http://site.cfp.org.br/wp-content/uploads/2012/03/ Resolucao_CFP_005_12_1.pdf

Conselho Federal de Psicologia. (2012b). Nota de orientação aos psicólogos(as). Recuperado em 30 dezembro, 2012, de: http:// www.crprs.org.br/noticias_internas.php?idNoticia $=1748$

Conselho Federal de Psicologia (2013). Relatório Ano Temático da Avaliação Psicológica 2011/2012. Recuperado em 20 abril, 2013, de: http://site.cfp.org.br/wp-content/ uploads/2012/12/264tico-de-Avaliacao-Psicologica_versaofinal.pdf

Costa, A. B., Peroni, R. O., Bandeira, D. R., \& Nardi, H. C. (2013).Homophobia or sexism? A systematic review of prejudice against nonheterosexual orientation in Brazil. International Journal of Psychology, 48(5), 900-9. doi: 0.1080/00207594.2012.729839

Edwards, A. L. (1954). Edwards personal preference schedule. New York: Psychological Corporation.

Foucault, M. (1998). História da sexualidade I: a vontade de saber. Rio de Janeiro: Graal.

Gardner, J. M. (1969). Indicators of homosexuality in the human figure drawings of heroin-and pill-using addicts. Perceptual and Motor Skills, 28(3), 705-706.

Gilman, S. L. (1985). Difference and pathology: Stereotypes of sexuality, race and madness. Ithaca, EUA: Cornell University Press.

Gonsiorek, J. C. (1991). The empirical basis for the demise of the illness model of homosexuality. In J. C. Gonsiorek \& J. D. Weinrich (Org.), Homosexuality: Research implications for public policy (pp. 115-136). Thousand Oaks, CA, EUA: Sage Publications.

Haas, A. P., Eliason, M., Mays, V. M., Mathy, R. M., Cochran, S. D., D'Augelli, A. R., \& Clayton, P. J. (2010). Suicide and suicide risk in lesbian, gay, bisexual, and transgender populations: Review and recommendations. Journal of Homosexuality, 58(1), 10-51. doi: 10.1080/00918369.2011.534038

Herek, G. M., Kimmel, D. C., Amaro, H., \& Melton, G. B. (1991). Avoiding heterosexist bias in psychological research. American Psychologist, 44(9), 957-963.

Herek, G. M. (2010). Sexual orientation differences as deficits: Science and stigma in the history of American Psychology. Perspectives on Psychological Science, 5(6), 693-699. doi: $10.1177 / 1745691610388770$

Hooker, E. (1957). The adjustment of the male overt homossexual. Journal of Projective Techniques, 21, 18-31.

Hooker, E. (1958). Male homosexuality in the Roscharch. Journal of Projective Techniques, 22, 33-54.

Hutz, C. S. (2009). A ética na avaliação psicológica. In C. S. Hutz (Org.), Avanços e polêmicas em avaliação psicológica (pp. 297-310). São Paulo: Casa do Psicólogo.

Irigaray, T. Q., \& Schneider, R. H. (2007). Características de personalidade e depressão em idosas da Universidade para a Terceira Idade (UNITI/UFRGS). Revista de Psiquiatria do Rio Grande do Sul, 29(2), 211-216. doi: http://dx.doi.
org/10.1590/S0101-81082007000200008

Kinsey, A. C., Pomeroy, W. B., \& Martin, C. E. (1948). Sexual behavior in the human male. Philadelphia: W. B. Saunders.

Lima, O. M. P., \& Noronha, A. P. P. (2005). Qualidade de testes psicológicos. Psic, 6(1), 65-71. Recuperado em 24 de maio 2013 de http://pepsic.bvsalud.org/pdf/psic/v6n1/v6n1a03.pdf

Murray, H. A. (1938). Explorations in personality. New York: Oxford University Press.

Noronha, A. P. P. (2002). Análise de testes de personalidade: qualidade do material, das instruções, da documentação e dos itens qualidade de testes de personalidade. Estudos em Psicologia, 19(3), 55-65. doi: http://dx.doi.org/10.1590/S0103166X2002000300006

Pasquali, L., Azevedo, M., \& Ghesti, I. (1997). Inventário fatorial de personalidade: Manual Técnico e de Aplicação. São Paulo: Casa do Psicólogo.

Pasquali, L. (2010). Instrumentação psicológica: fundamentos e práticas. Porto Alegre: Artmed.

Peres, R. S., \& Santos, M. A. dos. (2006). Contribuições do inventário fatorial de personalidade (IFP) para a avaliação psicológica de pacientes onco-hematológicos com indicação para o transplante de medula óssea. Psicologia em Revista, 12(19), 22-33.

Pope, M. (1992). Bias in the interpretation of psychological tests. In S. Dworkin \& F. Gutierrez (Org.), Counseling gay men and lesbians: Journey to the end of the rainbow (pp. 277-292). Alexandria, VA, EUA: American Counseling Association.

Primi, R. (2011). Responsabilidade e ética no uso de padrões de qualidade profissional na avaliação psicológica. In Conselho Federal de Psicologia, Ano da Avaliação Psicológica - Textos Geradores (pp. 53-57). Brasília: Conselho Federal de Psicologia.

Reppold, C. T. (2011). Qualificação da avaliação psicológica: critérios de reconhecimento e validação a partir dos direitos humanos. In Conselho Federal de Psicologia. Ano da Avaliação Psicológica - Textos Geradores (pp. 21-28). Brasília, DF: Autor

Rios, R. R. (2011). Direitos sexuais, uniões homossexuais e a decisão do Supremo Tribunal Federal (ADPF no 132-RJ e ADI 4.277). In R. R. Rios, C. Golin \& P. Leivas. Homossexualidade e direitos sexuais: reflexões a partir da decisão do STF (pp. 69114). Porto Alegre: Sulina.

Sepúlveda, M., van Banning, T., Gudmundsdóttir, G., Chamoun, C., \& van Genugten, W. (2004). Human rights reference handbook. Ciudad Colon, Costa Rica: University of Peace.

Snyder, J. E. (2011). Trend analysis of medical publications about LGBT persons: 1950-2007. Journal of Homosexuality, 58(2), 164-188. doi: 10.1080/00918369.2011.540171

Simões, A., \& Facchini, R. (2009). Na trilha do arco-íris: do movimento homossexual ao LGBT. São Paulo: Editora Fundação Perseu Abramo.

Weinberg, G. (1972). Society and the healthy homosexual. Nova York: St. Martin's Press.

Young-Bruehl, E. (1996). The anatomy of prejudices. Cambridge, MA: Harvard University Press. 